\title{
A RECEPÇÃO DOS DESENHOS ANIMADOS DA TV E AS RELAÇÕES ENTRE A CRIANÇA E O ADULTO: DESENCONTROS E ENCONTROS
}

\author{
Adriana Hoffmann Fernandes ${ }^{* *}$ \\ Maria Luíza Bastos Magalhães Oswald ${ }^{* * *}$
}

\begin{abstract}
RESUMO: Este artigo discute a complexidade das relações entre adultos e crianças na contemporaneidade, focalizando a recepção dos desenhos animados. A orientação teórico-metodológica adotada foi a dos Estudos Culturais Latino-Americanos, a qual, integrando os fenômenos da comunicação e da cultura e refutando a idéia de passividade diante da TV, defende que as mediaçōes que influenciam a recepção contribuem para a produção de sentidos sobre a assistência. Desse modo, optou-se por tomar a criança como produtora de cultura perante a TV. $\mathrm{O}$ artigo analisa os depoimentos de crianças na faixa etária dos 9, 10 anos de duas escolas, uma pública e uma particular, apontando as mediaçōes, relativas à audiência dos desenhos animados, que determinam desencontros e encontros entre crianças e adultos.
\end{abstract}

Palavras-chave: Desenhos animados. Cultura. Mediações.

O tema de discussão deste artigo já foi apresentado no II Seminário Internacional "As redes de conhecimento e a tecnologia: imagem e cidadania", ocorrido na Universidade do Estado do Rio de Janeiro (UERJ) em junho de 2003 e aprovado para apresentação no Congreso Iberoamericano de Comunicación y Educación "Luces em el laberinto audiovisual", em Huelva (Espanha), em outubro de 2003.

** Pedagoga, mestre em educação pela PUC-RJ e professora da Universidade Estácio de Sá. Atualmente é doutoranda do Programa de Pós-Graduação em Educação e professora contratada da Faculdade de Educação da UERJ.

*** Doutora em educação e professora da Faculdade de Educação da Universidade do Estado do Rio de Janeiro e do Departamento de Educação da Pontifícia Universidade Católica do Rio de Janeiro. E-mail: moswald@gbl.com.br

Cad. Cedes, Campinas, vol. 25, n. 65, p. 25-41, jan./abr. 2005

Disponível em <http://www.cedes.unicamp.br> 
A recepção dos desenhos animados da TV e as relações entre a criança e o adulto...

TV CARTOONS RECEPTION AND THE RELATIONS BETWEEN THE CHILD AND THE ADULT: DISAGREEMENTS AND AGREEMENTS

ABSTRACT: This article discuss the complexity of relationship among adults and children at the present time, emphasizing reception of TV cartoons. The theoretic-methodological orientation has been adopted from the Latin-American Cultural Studies which, aggregating with the phenomena of communication and culture and refuting the idea of passivity in front of the TV, defends that the mediations which influence the reception process contribute to the production of senses on watching. In this way, a child was chosen as culture producer in front of TV. The article analyses the statements of 9 and 10 years old children from two schools, one private and one public, pointing out the medations related to the cartoons audience, which determine the disagreements and agreements among children and adults.

Key words: Cartoons. Culture. Mediations.

\section{Introdução}

E ste artigo busca pensar as relações entre adultos e crianças na contemporaneidade, a partir de depoimentos de meninos e meninas, na faixa etária dos $9 / 10$ anos, a respeito de suas preferências sobre assistir a desenhos animados sozinhos. Os depoimentos foram selecionados do conjunto de dados colhidos por uma pesquisa de campo desenvolvida em duas escolas situadas na cidade do Rio de Janeiro, uma da rede pública e outra da rede privada, com o objetivo de entender a complexidade da relação da criança com a TV. ${ }^{1}$ Partindo do pressuposto de que a criança é produtora de cultura, de linguagem e de história, tomamos suas falas como "revelação dos valores fundamentais de uma dada sociedade e o modo como esses valores se explicitam e se confrontam" (Jobim e Souza, 2000, p. 139). Tal pressuposto guarda relação com a orientação teórico-metodológica do estudo, identificada com a abordagem dos Estudos Culturais Latino-Americanos (Gomez, 1991, 1993; Martin-Barbero, 2001), a qual, integrando os fenômenos da comunicação e da cultura, recusa a noção da passividade do sujeito, entendendo que as mediações no uso dos meios permitem que a recepção dos sujeitos se constitua como produção lógica de cultura. No primeiro item problematizamos a idéia de que as questôes que atravessam a contemporaneidade teriam agravado as relações criança/adulto forjadas pela 
modernidade. No segundo, sem ingenuidade em face das questões da atualidade determinantes do agravamento da ruptura do contato e do diálogo entre adultos e crianças, dispusemo-nos, a partir da visão da própria criança, a buscar saídas para esse mal-estar da nossa cultura interpretando que o uso da TV pode constituir-se, a partir das mediações, em tática viabilizadora de encontros.

\section{O que a concepção moderna de infância nos mostra sobre a relação criança/adulto}

Neil Postman (1999) atribui o nascimento da infância principalmente a dois fatores: à invenção da imprensa, que criou o homem letrado, e à escola, instituição responsável por desvelar o mundo das letras à criança. Não saber e saber ler se configura, do século XVI ao XX, no limiar por excelência que distinguia, no seio da burguesia, a experiência infantil da experiência adulta. Havia, ainda, um outro aspecto que distanciava adultos e crianças: a vergonha dos mais velhos com relação aos pequenos ante questôes como violência, sexo e palavras grosseiras contribuía para a construção de um clima de mistério e segredo que ensejava a autoridade dos primeiros para impor à infância diretrizes morais formadoras.

Segundo o autor, o não-saber constitutivo da infância - "as crianças são um grupo de pessoas que não sabem certas coisas que os adultos sabem" - dissolve-se, no contexto norte-americano, na "era da televisão" (idem, ibid., p. 99). Isso, tanto em razão da natureza da imagem, que, contrariamente à alfabetização, é legível imediatamente, tanto aos de 6 quanto aos de 60 , como do caráter de entrada franca da televisão que coloca adultos e crianças em pé de igualdade perante a informação. E, num mundo onde não há mais segredos, "evidentemente, não pode haver uma coisa como infância” (idem, ibid., p. 94). Resumindo-se os argumentos do autor, tem-se que a infância está em vias de desaparecimento porque, diante da televisão, não é mais possível manter-se a contradição adulto que sabe versus criança que não sabe, que vem se constituindo como fundamento da concepção moderna de infância. É importante destacar que a dimensão apocalíptica dos argumentos que Postman reúne para dar visibilidade ao suposto desaparecimento da infância é explicável em face da gravidade das questôes que o afligem, tais como a erotização precoce da criança, a crescente participação infanto-juvenil na criminalidade, o esmorecimento das brincadeiras que constituem a cul- 
A recepção dos desenhos animados da TV e as relações entre a criança e o adulto...

tura infantil, o empobrecimento das relações entre adultos e crianças etc. Obviamente, diante dessa realidade compartilhada pelo Brasil, não cabe a indiferença ou o sentimento de que esse seria o preço a pagar pelo progresso. Em contrapartida, a oposição acima referida, que o autor utiliza para demonstrar o declínio da infância, pareceu-nos inadequada para estimular a busca de alternativas propícias à (re)humanização das relações criança/adulto.

\section{Colocando em xeque a concepção moderna de infância}

Se a passagem do anonimato às Luzes, iniciada no século XVI e intensificada no XVIII, beneficiou a criança permitindo que fosse olhada com relação a sua alteridade, em contrapartida, o momento histórico e o contexto propícios à "invenção" da infância exigiram que o foco sobre ela se detivesse naquilo que lhe faltava, e que precisava ser preenchido para frutificar no homem burguês produtivo.

Jobim e Souza (1996) e Castro (1998a), referindo-se ao comprometimento da ciência com o projeto que a modernidade traçou para a infância, mostram como a psicologia contribuiu para definir a última como "a lenta preparação para a suposta vida produtiva” (Castro, 1998a, p. 35). Dois são os discursos que irão definir essa trajetória: o biológicoevolucionista, o qual, procedente das ciências da natureza e da medicina, vai inspirar estudos em que o desenvolvimento da criança é visto como embrionário das características humanas do adulto; e o pedagógico-normativo, que confere à psicologia do desenvolvimento o poder de legislar as relações adulto/criança com base em normas que, traduzidas em tarefas escolares e cotidianas, deveriam preencher a criança com aquilo que lhe faltava biologicamente para que ela pudesse ficar mais parecida com o modelo adulto.

Tais tarefas pressupõem aquela contradição entre adulto que sabe e criança que não sabe, cuja superação na "era da televisão" é identificada por Postman (1999) como responsável pelo desaparecimento da infância moderna. Embora levando em conta o perigo da generalização, não podemos deixar de evocar todo o mal-estar imposto às crianças em nome dessa contradição e que poderia ser resumido na máxima "cresça e apareça”. Poderíamos trazer para este texto uma infinidade de exemplos: da nossa própria infância, das infâncias que nos foram contadas por nossos 
pais e avós, das infâncias com as quais convivemos hoje, mas escolhemos para representá-las a infância de Bartolomeu Campos de Queiroz. Suas lembranças do tempo em que era menino nos mostram o quanto seria necessário refletir mais profundamente sobre o desalento de Postman (1999) em face do desaparecimento da infância moderna, cuja formulação pressupunha, e continua a pressupor, uma suposta menoridade da criança ante o adulto.

Bartolomeu Campos de Queiroz (1983, p. 27) começa assim seu texto, significativamente intitulado "Das saudades que não tenho...": "Nasci com 57 anos. Meu pai me legou seus 34, vividos com duvidosos amores, desejos escondidos. Minha mãe me destinou seus 23, marcados com traiçóes e perdas. Assim somados o que herdei foi a capacidade de associar o amor ao sofrimento".

E, ao longo do texto, ele vai mostrando o quanto a visibilidade alcançada pela criança moderna, além de, muitas vezes, não propiciar o lado bom da descoberta da infância - a paparicação de que fala Ariès (1983) -, também não a resguardava dos "segredos" dos adultos, como ainda a expunha ao arbítrio do ditado "é de pequenino que se torce o pepino".

Meu pai não passeou comigo montado em seus ombros, nem minha mãe cantou cantigas de ninar para me trazer o sono. Mesmo nascendo com 57 anos estava aos 60 obrigado a ser ainda criança. E ser menino era honrar o pai com seus amores ocultos. Gostar da mãe e seus suspiros de desventuras. Amar a Deus sobre todas as coisas, mesmo tendo a mão do vigário passeando sobre minhas pernas. (p. 27)

Tive uma educação primorosa. Minha primeira cartilha foi o olhar de meu pai, que me autorizava a comer ou não mais um doce nas festas de aniversário. Comer com a boca fechada, é claro, para ficar mais bonito e meu pai receber elogios pelo filho contido que ele tinha. E cada dia eu era visto como a mais exemplar das crianças, naquela cidade onde a liberdade nunca tinha aberto as asas sobre nós. (p. 28)

Claro que a coisa não era sempre feia desse jeito. Nem para Bartolomeu, nem para outras tantas crianças que tiveram/têm sua infância pautada pela lógica da modernidade. Nas memórias do autor aparecem momentos em que, longe dos olhares dos adultos, ele pintava e bordava. A vida é feita de contradições. Sendo assim, sem esquecer os herdeiros da infância de curta duração, a criança moderna, mesmo 
A recepção dos desenhos animados da TV e as relações entre a criança e o adulto...

diante das faltas jogadas no seu nariz, valeu-se de táticas que lhe permitiram gozar a plenitude de ser criança nos inúmeros intervalos da vigilância dos adultos, brincando nos quintais e nas ruas, conversando e rindo com companheiros de idade, praticando leituras e escritas proibidas, enfim pouco ligando para aquela outra contradição que a colocava na condição de não saber diante do adulto.

E a criança contemporânea, de que táticas ela lança mão para lidar com as "faltas" que limitam hoje suas relações com os adultos? Ser criança hoje é mais difícil do que foi ser criança ontem? A interação da criança com a televisão conduz necessariamente ao desaparecimento da infância? Ou a infância que a contemporaneidade anuncia é outra? Seria possível, tanto quanto é desejável, promover, hoje, o encontro entre crianças e adultos em bases mais solidárias que as que fundamentaram essas relações ontem?

\section{Relações criança/adulto na contemporaneidade: dos desencontros aos encontros}

Rio 40 graus/ Cidade maravilha/ Purgatório da beleza e do caos/ Capital do sangue quente do Brasil/ Capital do sangue quente/ Do melhor e do pior do Brasil/ Cidade sangue quente/ Maravilha mutante/ O Rio é uma cidade de cidades misturadas/ O Rio é uma cidade de cidades camufladas.

(Fernanda Abreu, Fausto Fawcet, Laufer)

A epígrafe acima representa, quase que visualmente, as contradições da cidade em que as crianças - sujeitos da pesquisa - habitam. Como diz a música, o Rio é o purgatório da beleza e do caos, capital do melhor e do pior do Brasil. Neste sentido, poderíamos dizer, tomando por inspiração a análise de Lessa (2001) sobre nossa pósmodernidade à brasileira, que, se num olhar de sobrevôo o que ressalta é a desordem, a violência, a ruptura dos laços tradicionais de solidariedade, o olhar mais de perto permite destacar dentre o caos a beleza, percebida na extroversão, na cordialidade, na opção pelo bate-papo animado nas esquinas, que o carioca, não obstante tudo, continua cultivando. Esse mesmo olhar de zoom poderia ser aplicado às relações criança/adulto, tão mutantes como é mutante a cidade em que tais rela- 
ções se desenvolvem. Ampliado, ele nos revelaria o quanto essas relações estão hoje empobrecidas... Mas e se o zoom fosse invertido, e passasse a colocar luz na peculiaridade das formas cotidianas de existência, não seria possível descobrir a beleza entremeando esse caos, e nos ajudando a construir novas maneiras de adultos e crianças se relacionarem? Para acompanhar a dimensão mutante da cidade, o foco da câmera deveria ser capaz de desconstruir a previsibilidade da contradição adulto que sabe/criança que não sabe, apostando na imprevisível sabedoria da criança como fez Walter Benjamin ao nos mostrar o quanto a incompetência infantil pode ser reveladora de verdades que os adultos não podem nem querem ouvir (Gagnebin, 1994, p. 93).

Filhos de inúmeras mudanças, as crianças e os jovens parecem se incomodar menos com elas que os adultos. Confortáveis diante da atribuição de tutelar a menoridade dos mais moços, os mais velhos inquietam-se, e culpam-se, diante da reviravolta cultural que, relativizando a oposição criança e adulto, inaugurou uma nova forma de educação da criança que tem como uma de suas forças motrizes a comunicação televisiva. Por isso a relação criança/TV se encontra no centro da cena, presente tanto nas empolgadas discussões informais que o assunto enseja como nos estudos transdisciplinares que congregam ao redor do tema os interesses da educação, da comunicação, da sociologia, da antropologia, da psicologia.

Situando o debate com relação ao que nos interessa discutir, colocamos em diálogo neste texto a revisão de bibliografia sobre as relações criança/adulto com algumas falas de meninas e meninos sobre sua preferência por assistir aos desenhos animados sozinhos ou acompanhados.

Cabe, primeiramente, dizer que todos os sujeitos da pesquisa, independentemente de inserção socioeconômica e da pluralidade de modos de ver TV, foram unânimes em demonstrar que a televisão ocupa um tempo significativo de suas vidas. Neste sentido, não é de estranhar a proliferação de estudos dedicados a investigar a influência da cultura televisiva sobre os comportamentos da criança. Gomez (1992) ressalta, entretanto, que grande parte desses estudos, centrados na noção de recepção passiva, condena a televisão por subordinar culturalmente a criança, vendo na proibição ou no controle dos programas a única forma de defender a infância contra a vilania desse meio de comunicação. Não foi essa a nossa perspectiva de estudo. Ao contrário, procuramos olhar 
A recepção dos desenhos animados da TV e as relações entre a criança e o adulto...

para a criança como receptor ativo, buscando descobrir que sentidos ela produz sobre sua preferência de assistir aos desenhos animados sozinha ou acompanhada. A construção desse olhar foi baseada tanto nos estudos sobre a infância que consideram a criança um ator social, sujeito de direitos, com capacidade e voz para influenciar seu próprio destino, quanto nos estudos latino-americanos sobre a recepção, os quais, colocando a presença dos mediadores socioculturais na relação entre sujeito e meios de comunicação, "introduzem novos sentidos do social e novos 'usos sociais' dos meios" (Martin-Barbero, 2001, p. 20).

\section{Desencontros}

Tanto na escola particular como na pública, a maioria das crianças ressaltou que prefere ver os desenhos sozinha. Essa preferência poderia ser interpretada com base no argumento de Postman (1999), de que com a liberação social da mulher teria havido "um declínio significativo na força e no significado dos padrões tradicionais de assistência à infância”. Neste sentido, as crianças, na ausência das figuras parentais, ficariam à mercê da chamada babá eletrônica. Pois não foi esse o sentido conferido pelos sujeitos da pesquisa à sua preferência. Segundo a maioria deles, o principal motivo de gostarem mais de ver TV sozinhos era o fato de que ver desenho junto com outras pessoas atrapalhava. O adulto foi apontado como um desses "atrapalhadores" da assistência. É interessante perceber como emerge dos depoimentos abaixo uma inversão dos lugares fixos que a modernidade determinou para crianças e adultos.

$\mathrm{Na}$ escola particular algumas crianças ressaltaram que quase todas as crianças sabem sobre os desenhos, pois "tirando os adultos que não vêem desenhos, só se for uma criança anta que não sabe!!”. Algumas crianças dessa escola argumentaram desta forma:

Eu não concordo. As crianças podem saber de uns desenhos e não saber de outros... Os adultos não sabem porque eles nunca vêem. Eu sou a única na minha casa que assisto. $\mathrm{O}$ meu pai, na casa dele, ainda vê aqueles desenhos antigos que eram da época dele como o Tom e Jerry e esses.

É... tem um desenho que era um cavalo e um outro que se chama Babalu que é um pequenininho... que é da época do meu pai. Eu nem sabia que esse desenho existia e ele sabia um monte de coisa... Então eu acho que alguns desenhos mais antigos eles sabem mais. Alguns desses que são do tempo deles... 
Esses depoimentos nos levam a pensar que tais situações trazidas pelas crianças apontam para nós adultos o novo lugar da criança como produtora de sentidos e de saberes, não mais totalmente dependente dos mais velhos. Para as crianças da pesquisa, os adultos não estão interessados em saber sobre desenhos, ou, quando se interessam, as experiências deles com os desenhos são outras. Como é o caso da preferência pelo famoso Tom e Jerry, identificado pelas crianças como "desenho do tempo deles". Um dos meninos apontou como percebe a relação dos adultos com os desenhos animados:

Eu acho que os adultos, por serem adultos, não sabem praticamente nada sobre desenhos animados. Porque quando a gente é criança a gente tem muito mais tempo e os adultos têm que trabalhar 24 horas por dia (...) só sobram as férias. Mas aí nas férias eles estão tão acostumados a não ver desenhos animados que eles nem querem mais ver. Então eles não ficam sabendo sobre desenhos... (Menino - escola particular)

Não saber é um dos motivos desse desencontro. Neste diálogo, as crianças da escola pública ressaltam o que percebem que os adultos não sabem:

- (...) o adulto quando vê não vai saber quem é o vilão, quem é o bom, quem é o mau...

- É... mas eles também não sabem o nome dos personagens, os poderes... Minha mãe sempre me pergunta se o personagem é do mal ou não.

- Meu pai (ou minha mãe) vê uns desenhos comigo e entende um pouco... Mas só um pouquinho...

- É que os adultos só entendem dos desenhos da época deles!

Os depoimentos anteriores permitem estranhar os argumentos de Postman (1999) de que, diante da TV - "meio que escancara tudo" -, crianças e adultos estão em pé de igualdade, fato que, segundo ele, seria responsável por demarcar o desaparecimento da infância. Mesmo reconhecendo que o autor pode ter razão relativamente a alguns programas, a preferência das crianças pelos desenhos animados incita uma outra interpretação: a de que, diante dessa programação, a relação criança/adulto fica invertida, passando a primeira a deter segredos e mistérios que eram antes exclusividade dos mais velhos. Se para a modernidade a experiência de ser criança estava associada, entre outras coisas, a não saber ler, hoje essa experiência inclui o saber sobre os desenhos. A falta desse sa- 
A recepção dos desenhos animados da TV e as relações entre a criança e o adulto...

ber é o principal motivo do desencontro entre adultos e crianças com relação à assistência dos desenhos. Assim, o adulto que "não sabe" pergunta sobre o desenho durante o desenho, e esse "perguntar", além de denotar o seu não-saber, atrapalha.

Escola pública:

- Tem criança que vai conversar com os pais sobre o desenho e o pai não sabe nada do desenho.

- Isso acontece comigo, falou outro.

Escola particular:

Pesq.: - Você acha que isso (saber sobre desenhos diferentes) dificulta ou facilita quando você vai conversar com os adultos e você sabe uma coisa e eles sabem de outras?

Criança: - Dificulta um pouco porque eles estão acostumados a ver aqueles desenhos que têm aquele vilão e às vezes é meio idiotinha...

Nessas falas das crianças percebe-se que o "não-saber" também pode ser um outro saber. A dificuldade de troca com o adulto nem sempre se refere ao não-saber dele, mas ao fato de o saber dele trazer referências de desenhos que nem sempre correspondem aos desenhos da atualidade. $\mathrm{O}$ diálogo entre criança e adulto, nessas circunstâncias, depende da disponibilidade de ambos para que um possa entender as referências do outro. Se o adulto não participa de nenhum desses espaços de significação em que a criança elabora o que vê na TV, fica, de certa forma, alijado desse conhecimento, limitando sua capacidade de troca com a criança.

\section{Encontros}

Se, por um lado, para algumas crianças essa diferença, ou não saber, pode dificultar o encontro e o diálogo, para outras ela pode ser um motivo de encontro, por iniciativa seja da criança, seja do adulto, como se observa nas falas a seguir:

- Eu costumo conversar com o meu avô assim: 'Vô, você já viu o desenho tal?' Aí ele: 'Não, me diz como é que é.' Aí eu explico lá para ele, depois ele vê e a gente fica conversando... (Menino - escola pública)

- Minha mãe não sabe, mas aí ela pergunta, eu conto e a gente fica conversando. (Menino - escola pública) 
Estes depoimentos apontam para uma outra forma de relação adulto/criança não mais baseada na supremacia do saber dos mais velhos sobre o dos mais jovens, o que possibilita, segundo Castro (1998b), uma democratização do lugar social da criança vis-à-vis ao do adulto, inexistente nas práticas socializatórias da sociedade moderna (p. 72). Sem deixar de atentar para o que há de massificante e assujeitador na cultura midiática, a autora supõe que os processos de telecomunicação trouxeram para a infância uma nova forma de reconhecimento social, diferente daquela que, baseando-se num processo seqüencial de credenciamento, adiava para crianças e jovens o direito de participar, de acordo com suas especificidades, da construção coletiva da sociedade (p. 61-62). Os grifos nas falas das crianças anteriormente referidas mostram o quanto é simplificador analisar a assistência à TV, especificamente no caso dos desenhos animados, como um meio de manipulação. Contrariamente, os meninos permitem que se vislumbrem os desenhos como mediação do encontro de alteridades:

A criança precisa do adulto, enquanto um "alter", como um "outro" diferente, para se constituir como sujeito e se lançar continuamente para além de si mesma em busca de seus projetos e utopias. Por outro lado, a criança também encarna um "alter" para o adulto. Sendo a infância a humanidade incompleta e inacabada do homem, talvez ela ainda possa nos indicar o que há de mais verdadeiro no pensamento humano: a sua incompletude, mas, também, toda a criação que se prenuncia, ou melhor, a invenção do possível. (Jobim e Sousa, 2000, p. 97)

Gomez (1991) explica este encontro de alteridades mostrando que a recepção e a produção de significados acerca do que é visto ocorrem nos vários espaços sociais em que a criança circula. As crianças apropriam-se do que vêem na TV a partir de inúmeras mediaçôes, como, por exemplo, as conversas com amigos e familiares. De acordo com o autor, as crianças não nascem televidentes, mas constituem-se como tal por intermédio da intervenção implícita ou explícita de diversos agentes sociais. Assim, conversar sobre o desenho pode estar prenunciando a criação de uma das narrativas possíveis na pós-modernidade. "Nos lares de hoje as famílias não mais contam suas histórias", mas podem se encontrar para conversar e trocar experiências sobre desenhos animados, como mostra uma das crianças da escola particular quando diz que, ao compartilhar os desenhos com ela, os adultos parecem "crianças": 
A recepção dos desenhos animados da TV e as relações entre a criança e o adulto...

- O meu avô se enche de Coca-Cola e pipoca e vê os desenhos junto comigo; a minha avó dorme no meio do desenho... A minha mãe quando vê desenho comigo fala: 'Ah, eu queria ser ela' [a personagem]. Minha mãe parece uma criança! (Menina - escola particular)

Parecer criança é ver desenho como uma criança dizendo: "Ah, queria ser como ela!", sonhando e se identificando com os personagens preferidos que aparecem na tela. E veja-se que, quando a criança diz que a mãe parece uma criança, ela pode estar querendo elogiar, mas pode também estar trocando de lugar com a mãe, sorrindo entre dentes como a mãe faria diante da infantilidade da filha. Não seria este um indício de que o adultocentrismo que marcou as relações criança-adulto durante séculos não foi suficiente para convencer a criança de sua condição de menoridade, de ser em preparação? Saber mais que o adulto (pelo menos em alguns setores da vida), poder trocar de lugar com o adulto algumas vezes não parece mais gratificante que ter de esperar crescer para aparecer? Sem abandonar o foco ampliado do zoom que vem mostrando que a inversão dos "lugares de experiência" de adultos e crianças precisa ser analisada criteriosamente para que o outro lado da face "superpoderosa" da criança não seja o da "esquecida" (Pereira, 2000), seria bom ouvir o que Certeau (2000) tem a dizer sobre a importância do movimento de aproximação do zoom. Desconfiando da idéia que associa consumidores à passividade e disciplina, o autor pondera que a análise das imagens da televisão e do tempo que se passa diante dela deveria ser completada pelo estudo sobre o que o consumidor cultural "fabrica" com isso. A fabricação, segundo ele, é uma produção escondida

(...) porque ela se dissemina nas regióes definidas e ocupadas pelos sistemas da "produção" (televisiva, urbanística, comercial etc.) e porque a extensão sempre mais totalitária desses sistemas não deixa aos "consumidores" um lugar onde possam marcar o que fazem com os produtos. A uma produção racionalizada, expansionista além de centralizada, barulhenta e espetacular, corresponde outra produção, qualificada de "consumo": esta é astuciosa, é dispersa, mas ao mesmo tempo ela se insinua ubiquamente, silenciosa e quase invisível, pois não se faz notar com produtos próprios mas nas maneiras de empregar os produtos impostos por uma ordem econômica dominante. (p. 39)

Diante disso, não seria possível olhar para a inversão dos lugares que a criança e o adulto ocupam diante dos desenhos animados como uma "fabricação" de novas formas de relacionamento? 


\section{Considerações finais: em busca de novos encontros}

Colocamos em xeque neste texto as relações entre adultos e crianças ensejadas pela concepção moderna de infância, considerando que a oposição adulto que sabel criança que não sabe não tem sido suficiente para qualificar tais relaçōes. Mesmo compreendendo e nos preocupando com os motivos que levaram Postman (1999) a defender a tese do "desaparecimento da infância", perguntamo-nos se a televisão, como "meio que escancara tudo", colocando crianças e adultos em pé de igualdade diante da informação, poderia ser tão enfaticamente responsabilizada por isso. Mesmo porque, se a televisão é uma das inovaçōes tecnológicas responsáveis pelo empobrecimento das relações sociais contemporâneas, em contrapartida, lembrando Benjamin (1985a, p. 225), caberia refletir sobre o fato de que o patrimônio cultural legado pela tradição também não foi capaz de enriquecê-las. E, para o autor, a chorar pelo leite derramado, o preferível seria assumir essa pobreza de experiência que poderia, afinal, traduzir um "conceito novo e positivo de barbárie", que impeliria o homem a começar de novo como se fosse tábula rasa. Segundo ele:

Algumas das melhores cabeças já começaram a ajustar-se a essas coisas. Sua característica é uma desilusão radical com o século e ao mesmo tempo uma total fidelidade a esse século. (...) Tanto um pintor complexo como Paul Klee quanto um arquiteto programático como Loos rejeitam a imagem do homem tradicional, solene, nobre, adornado com todas as oferendas do passado, para dirigir-se ao contemporâneo nu, deitado como um recémnascido nas fraldas sujas de nossa época. (Benjamin, 1985b, p. 116)

Embora quase 70 anos nos separem dessas palavras do autor, sua lucidez atinge-nos em cheio. Não se trata aqui de fazer mau uso da teoria crítica benjaminiana, insinuando que o autor estaria nos convidando a nos ajustarmos ao continuum da História. A fazer isso, seria melhor "esquecer Benjamin", como adverte Sarlo (1997), lembrando que "Benjamin pode ser considerado um escritor da crise, mas não seu apologista" (p. 103).

O exercício de lembrar Benjamin permitiu que não descolássemos nosso olhar do contexto mais amplo que vem sustentando a crise das relações adulto/criança. Neste sentido, estamos cientes de que a concepção de infância que a contemporaneidade vem esboçando, que elevou a criança ao status de consumidora, não é uma dádiva do progresso, mas é 
A recepção dos desenhos animados da TV e as relações entre a criança e o adulto...

fruto do lugar que o mercado reservou à infância, destinando-lhe, inclusive, o papel de ser cliente de desenhos animados que irão gerar, em escala vertiginosa, o fortalecimento da cultura do consumo. Mas, se diante da totalidade nos sentimos impotentes para conter os efeitos desse suposto progresso, é preciso, como Benjamin (1985a, p. 223) mesmo considera, assumir a posição do cronista que faz história a partir dos pequenos acontecimentos.

Assim, se não podemos interferir diretamente no sistema de produção televisiva - uma das formas culturais mais poderosas do capitalismo pós-industrial -, que impõe às crianças e aos jovens o risco da massificação e da subordinação cultural, nada nos impede de "fabricar" maneiras de driblar esse risco. As crianças constituem-se, a partir de suas preferências pelos desenhos, em comunidades interpretativas, e cabe a nós poder colocar nosso pé dentro dessa comunidade para poder entender e construir com ela o sentido dos desenhos, para que sejamos participantes desse espaço e não invasores.

Gomez (1993) define a comunidade interpretativa como um grupo de sujeitos sociais unidos por um conjunto particular de práticas sociais das quais surgem televidências (usos da TV) específicas. E fazer parte dessa "comunidade" é estar em pé de igualdade, é poder estabelecer uma troca não-hierárquica baseada num conhecimento comum que favoreça a troca, o diálogo. Algumas crianças reconheceram em seus depoimentos que, mesmo podendo haver troca entre adultos e crianças, é muito difícil encontrar por aí "adultos que parecem crianças". Neste sentido, as trocas de saberes sobre os desenhos acontecem, em sua maioria, entre seus próprios pares: os amigos da escola. São eles os pares por excelência dessa produção de significados dos desenhos. Entretanto, o exame das falas das crianças mostra que tais desencontros estão longe de ser incontornáveis. Afinal, a crítica das crianças aos adultos, tanto as da escola particular quanto as da escola pública, revela mais sua proximidade com tais adultos que a ausência deles. Conhecem e entendem a preferência dos pais com relação aos desenhos, justificam a "ignorância" dos adultos pela falta de tempo, enfim, colocam-se no lugar do adulto, olhando-o nos seus próprios termos. Há, em contrapartida, crianças que reconheceram os adultos como interlocutores capazes, estabelecendo com eles uma comunidade interpretativa. Como demonstra o diálogo a seguir, um dos critérios para esse reconhecimento é o de que o adulto se coloque à altura da criança. 
Pesq.: - Você acha que quando vocês crescerem vão deixar de ver desenhos? Menino: - Bom, tem adultos que permanecem com o seu lado infantil...

Menina: - Como a minha mãe...

Enfim, o contato com essas falas das crianças nos levou à interpretação de que, ao possibilitar a suspensão da oposição adulto que sabe/ criança que não sabe, a TV, no que se refere à assistência aos desenhos animados, pode ser instauradora do encontro e do diálogo entre crianças e adultos. Estar em pé de igualdade com o adulto aqui não nos fez evocar o desaparecimento da infância, mas uma experiência de infância lúcida, coerente e crítica.

Recebido em fevereiro de 2005 e aprovado em março de 2005.

\section{Nota}

1. Trata-se da dissertação de mestrado de Adriana Hoffmann Fernandes, orientada por Maria Luíza Oswald, no Programa de Pós-Graduação do Departamento de Educação da PUCRIO. A pesquisa, do tipo etnográfica, foi realizada por meio de observaçōes intensivas, entrevistas com as crianças utilizando um gravador e videogravações de oficinas envolvendo a discussão e a produção de desenhos e de textos escritos a partir dos seguintes desenhos animados: Sakura, Os Simpsons, As meninas superpoderosas, Ginger e Pokemon. O campo empírico foi constituído por 5 meninos e 7 meninas da escola particular e 10 meninos e 14 meninas da escola pública.

\section{Referências bibliográficas}

ARIÈS, P. História social da criança e da família. Rio de Janeiro: Guanabara Koogan, 1983.

BENJAMIN, W. Experiência e pobreza. In: Benjamin, W. Obras escolhidas I: magia e técnica, arte e política. Trad. de Sergio Paulo Rouanet. São Paulo: Brasiliense, 1985a.

BENJAMIN, W. Sobre o conceito de história. In: Benjamin, W. Obras escolhidas I: magia e técnica, arte e política. Trad. de Sergio Paulo Rouanet. São Paulo: Brasiliense, 1985b.

CASTRO, L.R. Uma teoria da infância na contemporaneidade. In: CAstro, L.R. (Org). Infância e adolescência na cultura de consumo. Rio de Janeiro: NAU, 1998a. 
A recepção dos desenhos animados da TV e as relações entre a criança e o adulto...

CASTRO, L.R. Consumo e a infância barbarizada: elementos da modernização brasileira? In: CASTRO, L.R. (Org.). Infância e adolescência na cultura de consumo. Rio de Janeiro: NAU, 1998b.

CERTEAU, M. A invenção do cotidiano 1: artes de fazer. 5. ed. Trad. de Ephraim Ferreira Alves. Petrópolis: Vozes, 2000.

GAGNEBIN, J.M. A criança no limiar do labirinto. In: Gagnebin, J.M. História e narração em Walter Benjamin. São Paulo: Perspectival FAPESP; Campinas: UNICAMP, 1994.

GOMEZ, G.O. Mediaciones familiares y escolares en la recepcion televisiva de los niños. Revista Brasileira de Comunicação, São Paulo, n. 64 , p. 8-19, jan./jun. 1991.

GOMEZ, G.O. Hacia uma dialectica de la recepcion televisiva: la estructuración de estratégias por los televidentes. Revista Comunicação e Política, Brasília, v. 18, n. 22-25, 1993.

GONDRA, J. (Org.). História, infância e escolarização. Rio de Janeiro: 7 Letras, 2002.

JOBIM E SOUZA, S. Re-significando a psicologia do desenvolvimento: uma contribuição crítica à pesquisa da infância. In: Kramer, S.; Leite, M.I. (Org.). Infância: fios e desafios da pesquisa. Campinas: Papirus, 1996.

JOBIM E SOUZA, S. Conversando com crianças sobre escola e conhecimento: a abordagem dialógica e a crítica do cotidiano. In: JoBIM E SouzA, S. (Org). Subjetividade em questão: a infância como crítica da cultura. Rio de Janeiro: 7 Letras, 2000.

LESSA, C. Rio: pós-modernidade à brasileira, In: LesSA, C. O Rio de todos os Brasis: uma reflexão em busca de auto-estima. 2. ed. Rio de Janeiro: Record, 2001.

MARTIN-BARBERO, J. Dos meios às mediaçôes: comunicação, cultura e hegemonia. 2. ed. Trad. de Ronald Polito e Sergio Alcides. Rio de Janeiro: UfRJ, 2001.

PEREIRA, R.R. et al. Ladrões de sonhos e sabonetes: sobre os modos de subjetivação da infância na cultura do consumo. In: Jobim E 
SouzA, S. (Org.). Subjetividade em questão: a infância como crítica da cultura. Rio de Janeiro: 7 Letras, 2000.

PEREIRA, R.R. Tudo ao mesmo tempo agora: consideraçôes sobre a infância no presente. In: Gondra, J. (Org.). História, infância e escolarização. Rio de Janeiro: 7 Letras, 2002.

POSTMAN, N. O desaparecimento da infância. 3. ed. Trad. de Suzana Menescal de A. Carvalho e José Laurenio de Melo. Rio de Janeiro: Graphia, 1999.

QUEIROZ, B.C. Das saudades que não tenho... In: Abramovich, F. (Org). O mito da infância feliz. São Paulo: Summus, 1983.

SARLO, B. Esquecer Benjamin. In: SArlo, B. Paisagens imaginárias. Tradução de Rubia Prates e Sergio Molina. São Paulo: Edusp, 1997. 